1 Supporting Information for

2 Time-Resolved Single-Cell Assay for Measuring Intracellular Reactive Oxygen

3 Species upon Exposure to Ambient Particulate Matter

4

$5 \quad$ Fobang Liu ${ }^{1}$, Josh Whitley ${ }^{1}$, Nga Lee $\mathrm{Ng}^{1,2,3^{*}}, \operatorname{Hang} \mathrm{Lu}^{1 *}$

6

$7{ }^{1}$ School of Chemical \& Biomolecular Engineering, Georgia Institute of Technology,

8 Atlanta, Georgia 30332, United States

$9{ }^{2}$ School of Earth \& Atmospheric Science, Georgia Institute of Technology, Atlanta,

10 Georgia 30332, United States

$13^{3}$ School of Civil \& Environmental Engineering, Georgia Institute of Technology,

12 Atlanta, Georgia 30332, United States

13

14 Corresponding authors

$15 *$ *mail: hang.lu@gatech.edu; ng@chbe.gatech.edu

16

17 Number of pages: 12

18 Number of figures: 8

19 Number of tables: 1 
Evaluation of adhesive protein performance and cell membrane integrity after overnight cell culture in microfluidic device
Murine alveolar macrophages (MH-S) are adherent cells that must be cultured on a suitable substrate that allows cell adhesion and spreading. The glass substrate of the microfluidic devices does not directly support the attachment of MH-S. Hence, surface coating of a suitable adhesive protein on glass substrate is critical to culture cells in the microfluidic devices. Table S1 summarizes the results of cell attachment fraction and cell viability for each adhesive protein. Type I collagen shows a poor attachment performance (35\%) for MH-S. In contrast, $\mathrm{MH}-\mathrm{S}$ adhered well (63\%) to heat-denatured type I collagen. This result is consistent with previous studies ${ }^{1,2}$ showing that macrophages adhere favorably to the denatured form but not the native form of type I collagen via their scavenger receptors. ${ }^{1}$ Other adhesive proteins, i.e., poly-L-lysine, fibronectin, and gelatin, all have large cell attachment (> 70\%) to MH-S. Among them, poly-L-lysine has the largest cell attachment. The positively charged ions on the surface of poly-L-lysine makes it hydrophilic and may enhance the electrostatic interaction with negatively charged ions in the cell membrane. ${ }^{3}$ Cell viability was then qualitatively evaluated using trypan blue after cells were seeded on each adhesive protein and incubated overnight. The cell viability results (Table S1) show that most cells cultured on poly-L-lysine-coated substrate were dead, indicating that $100 \mu \mathrm{g} / \mathrm{mL}$ poly-L-lysine is toxic to MH-S, which might be caused by the fusion of the cell membrane. ${ }^{4}$ In contrast, cells were viable after overnight culture on the other adhesive proteins. Together, the cell attachment and viability results suggest that fibronectin and gelatin can be absorbed onto glass substrate to culture $\mathrm{MH}-\mathrm{S}$ in the microfluidic devices. To be consistent, only fibronectin was used as the adhesive protein for cell attachment in our established protocol where we employed the cell trap device for single-cell ROS measurement.

We further quantitatively determined the quality of plasma membrane integrity (an important indicator of cell viability) after culturing cells overnight on fibronectincoated substrate of a cell trap device using a dead cell fluorescent probe (Invitrogen). Membrane integrity was also determined two hours after adding the dead cell fluorescent probe to test if the damage to membrane integrity increased during the 120min imaging time at room temperature. Compared to cells fixed in ethanol used as a positive control (Figure S2-d), cells cultured on fibronectin coated substrate (Figures 
53 S2-b and c) show much less fluorescent intensity. The quantitative result in Figure S2-

54 e shows that the damage to membrane integrity of cells cultured using our established 55 protocol is significantly lower $(p<0.001)$ than the positive control, i.e. only $20 \%$ 56 relative to cells fixed in ethanol. Moreover, the 120-min imaging process did not have 57 an impact on cell membrane integrity as the fluorescent intensity between the beginning 58 and the end of the imaging process was not significantly different. Hence, our results 59 demonstrated that culturing $\mathrm{MH}-\mathrm{S}$ on fibronectin-coated substrate of cell trap device 60 does not significantly alter their health.

61

62 Table S1. Cell attachment fraction and live-cell percentage of each adhesive protein

\begin{tabular}{ccccc}
\hline $\begin{array}{c}\text { Adhesive } \\
\text { protein }\end{array}$ & Coating condition & $\begin{array}{c}\text { Cell attachment } \\
(\%)\end{array}$ & $\begin{array}{c}\text { Live-cell } \\
\text { percentage }(\%)^{*}\end{array}$ & comment \\
\hline fibronectin & overnight at $37^{\circ} \mathrm{C}$ & $82 \pm 3$ & $86 \pm 2$ & \\
collagen & overnight at $37^{\circ} \mathrm{C}$ & $35 \pm 3$ & $80 \pm 2$ & $\begin{array}{c}\text { One more } \\
\text { denature step } \\
\left.\text { (95 }{ }^{\circ} \mathrm{C}, 5 \text { min }\right) \\
\text { compared to } \\
\text { other choices }\end{array}$ \\
$\begin{array}{c}\text { denatured } \\
\text { collagen }\end{array}$ & overnight at $37^{\circ} \mathrm{C}$ & $63 \pm 3$ & $83 \pm 3$ & $84 \pm 3$ \\
$\begin{array}{c}\text { gelatin } \\
\text { poly-L- } \\
\text { lysine }\end{array}$ & overnight at $37^{\circ} \mathrm{C}$ & $77 \pm 2$ & $27 \pm 2$ & \\
\hline
\end{tabular}

64 in a microfluidic device. 

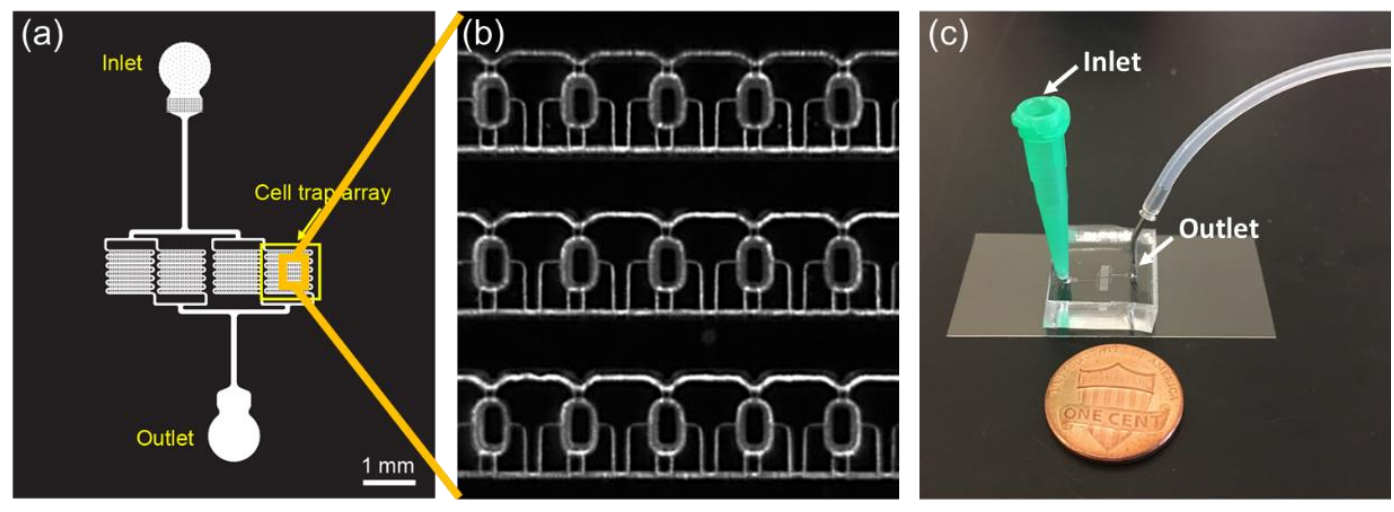

66 Figure S1. (a) Overview of a microfluidic device (drawn by AutoCAD). (b) Image of 67 a cell-trap array. (c) Image of a PDMS device. 
(a) TO, BF

(b) TO

(c) T120

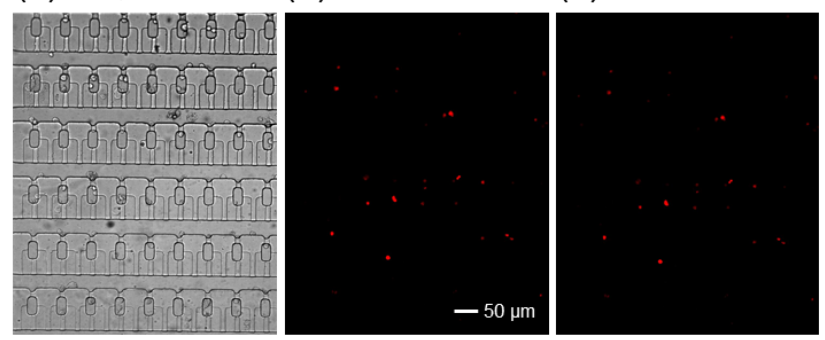

(d) Fixed in Ethanol
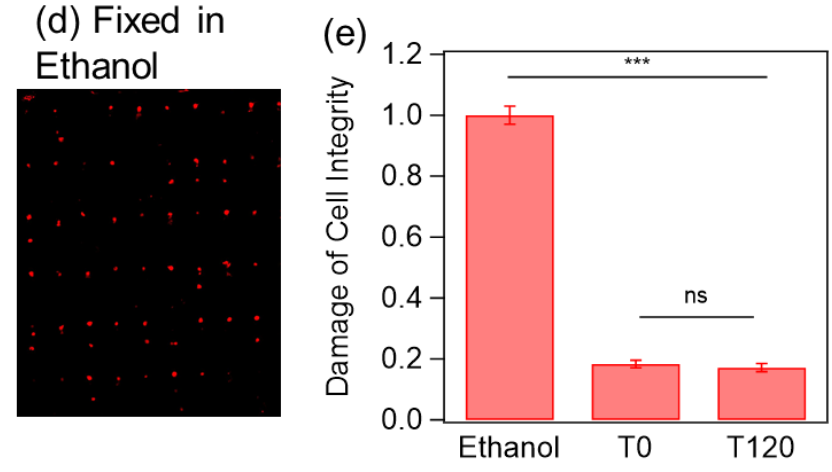

70 Figure S2. Cell membrane integrity after overnight cell culture in fibronectin-coated

71 substrate of a microfluidic cell trap device. (a) and (b) are brightfield (BF) and

72 fluorescent images of cells at the beginning of imaging after overnight culture. (c) is

73 fluorescent image at the end of 2-hr imaging. (d) is a fluorescent image of cells fixed in

74 ethanol (positive control, cell membrane is considered completely damaged by

75 ethanol). (e) is normalized damage of membrane integrity to cells fixed in ethanol. Error

76 bars represent standard errors calculated from single-cell measurements. *** indicates

$77 \quad p<0.001$. n.s. denotes not significant.

78 


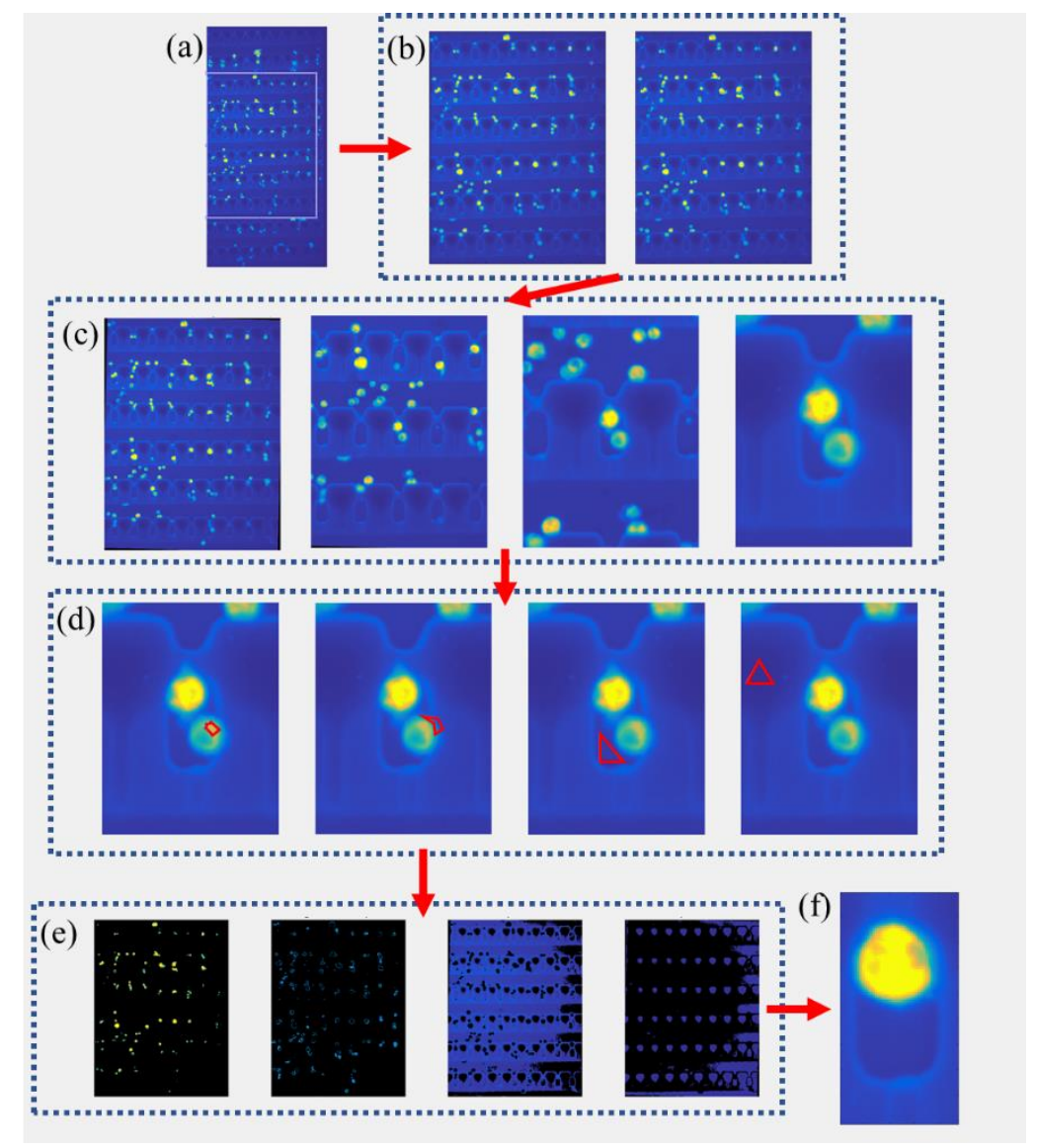

80 Figure S3. Phases of MATLAB image analysis presented pictorially. (a) The image is

81 cropped to the middle six rows and left-most nine columns to minimize the brightness

82 gradient present in the images during the analysis. The brightness gradient interferes

83 with image analysis and is best described by comparing the brightness of the bottom

84 left corner to the middle left of the image in (a). (b) The user selects two points on the same row to correct image skew. (c) The user zooms in to a cell chamber that contains

86 a high-brightness cell, a cell/cell chamber interface with ambiguous brightness, a cell

87 chamber, and structural PDMS. (d) The user creates bounded sections representative of 88 each of the four brightness categories (high-brightness cells, cell/cell chamber 89 interfaces with ambiguous brightness, cell chambers, and structural PDMS). (e) Four 90 layers are produced by comparing each pixel in the cropped image to the four selections 91 shown in (d). (f) An arbitrary cell chamber in the matrix, found by interpolating 92 between the positions of the corner cell chambers representing the scale at which 93 chamber brightness is subtracted from cell brightness to yield cell brightness relative to 94 background brightness on a per-chamber basis. 

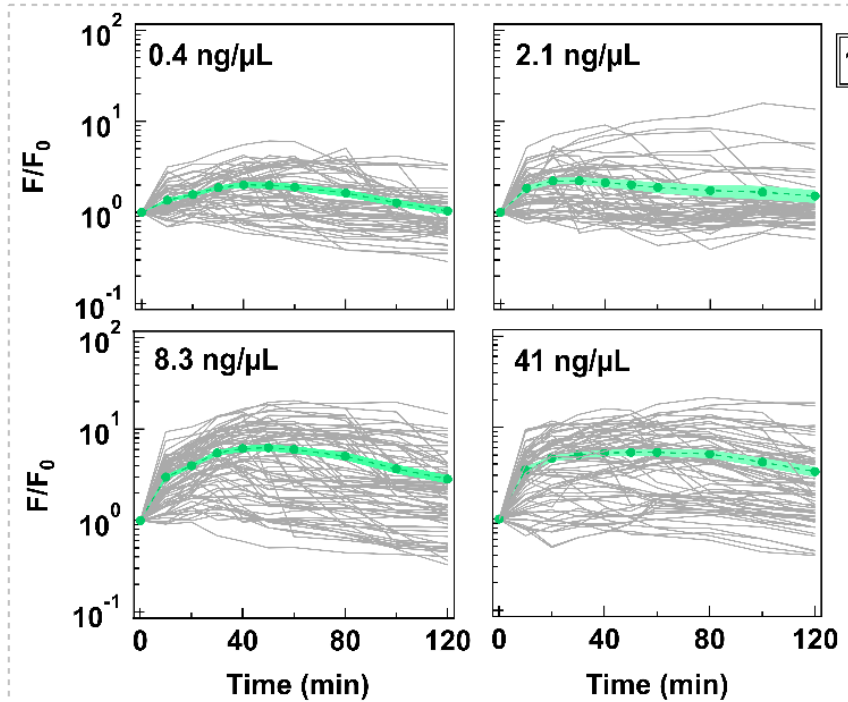

\section{1st trial}
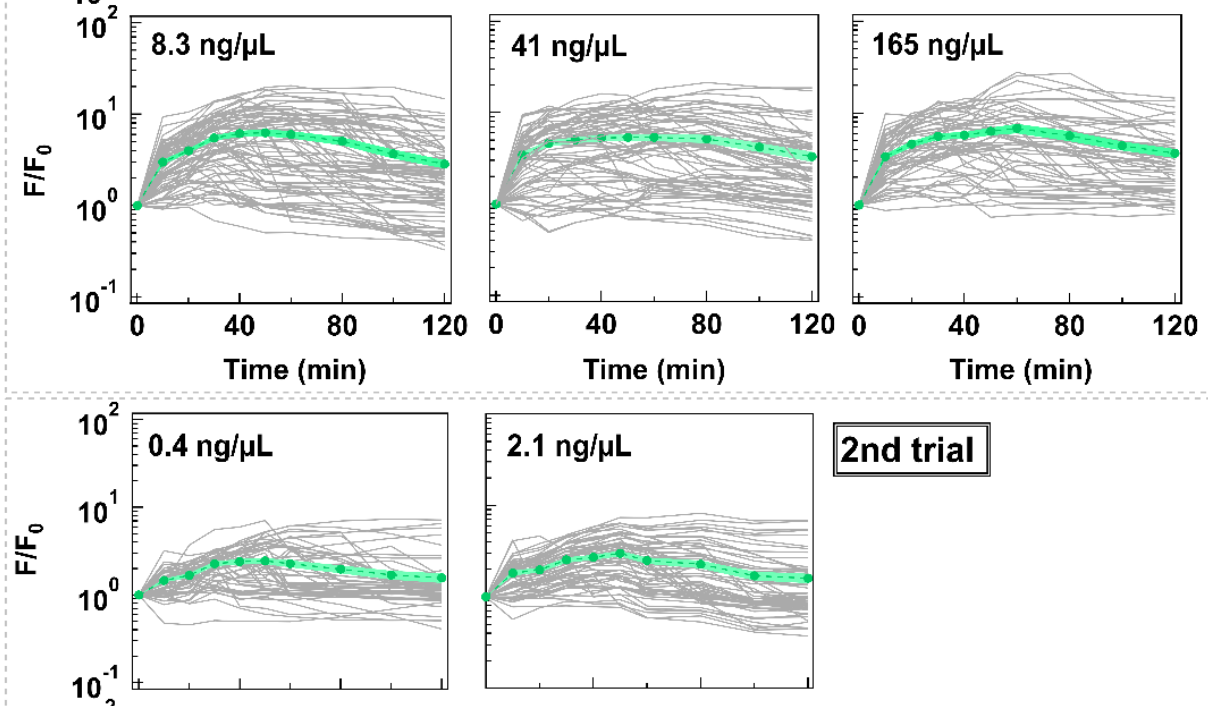

\section{2nd trial}
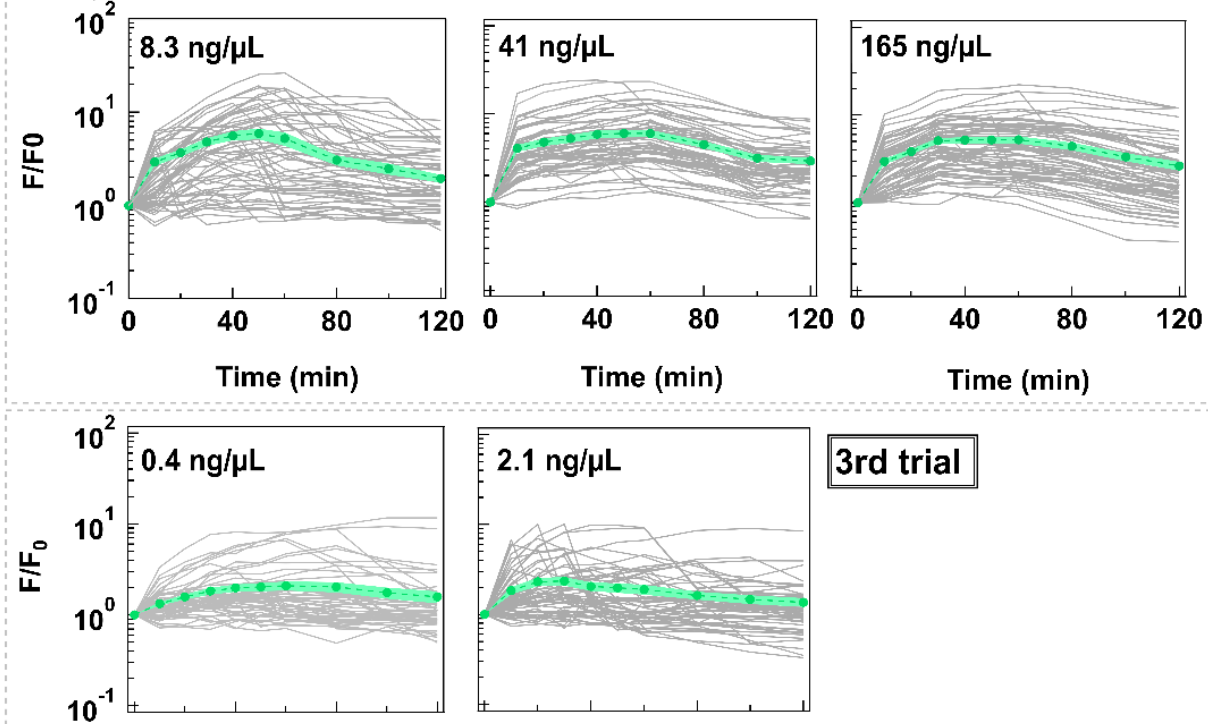

\section{3rd trial}
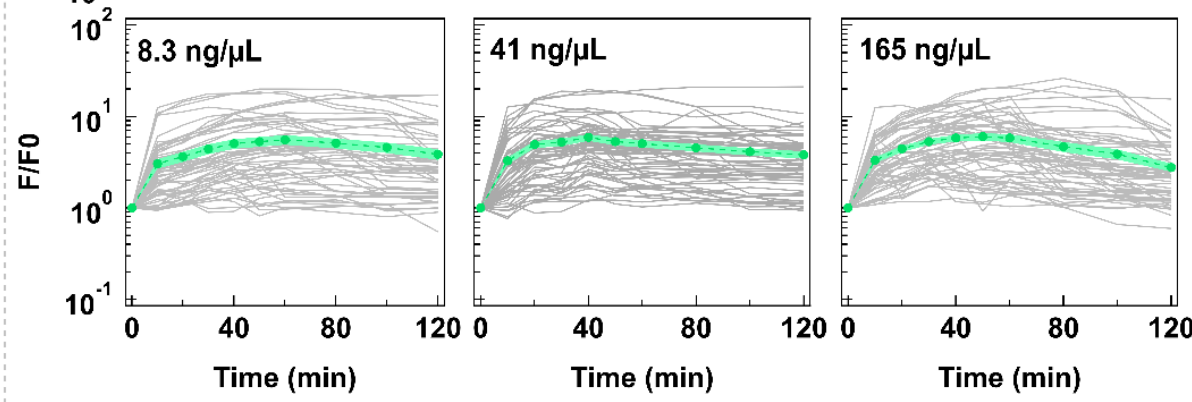

96 Figure S4. Single-cell (grey solid line) and average (green dashed line) traces of ROS

97 responses $\left(\mathrm{F} / \mathrm{F}_{0}\right)$ induced by five different concentrations of the PM extracts in three 98 independent trials. The green shades indicate the standard errors of average $F / F_{0}$. 

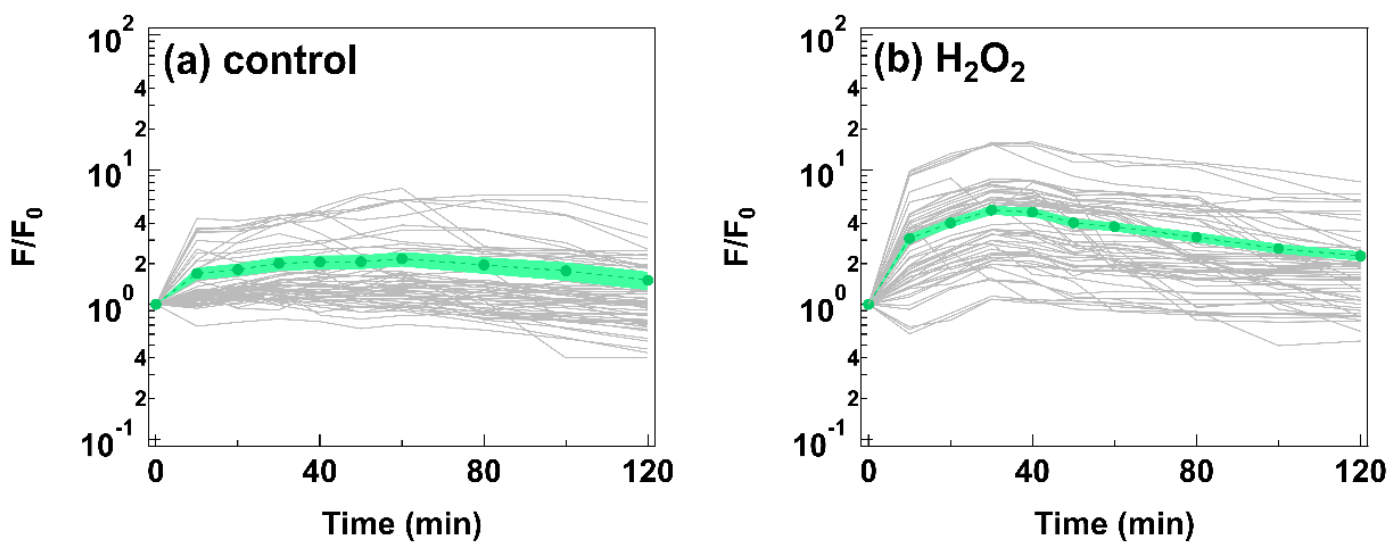

99

Figure S5. Representatives of single-cell (grey solid line) and average (green dashed

101 line) traces of ROS responses ( $\left.\mathrm{F} / \mathrm{F}_{0}\right)$ in control (cells exposed to PBS only, no stimulant)

102 and positive control $\left(100 \mu \mathrm{M} \mathrm{H}_{2} \mathrm{O}_{2}\right)$ samples. The green shade indicates the standard 103 error of average $\mathrm{F} / \mathrm{F}_{0}$.

104 


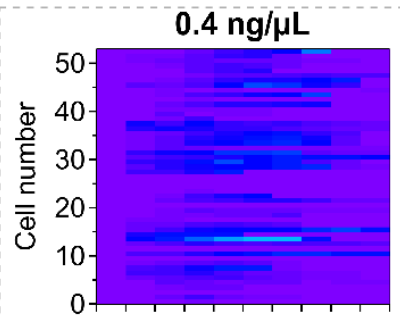

$8.3 \mathrm{ng} / \mu \mathrm{L}$

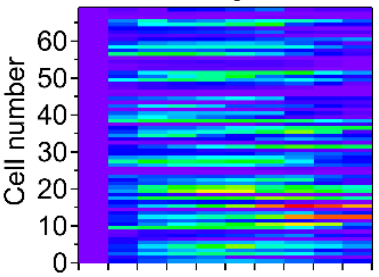

$0.4 \mathrm{ng} / \mu \mathrm{L}$

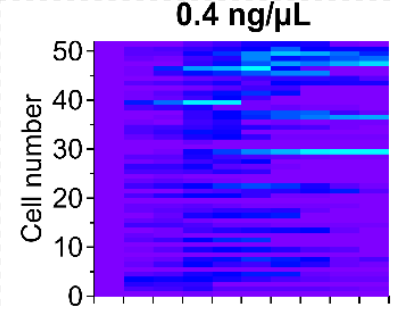

$8.3 \mathrm{ng} / \mu \mathrm{L}$

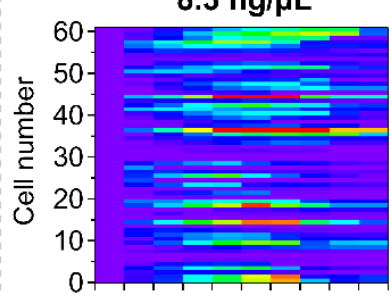

$0.4 \mathrm{ng} / \mu \mathrm{L}$

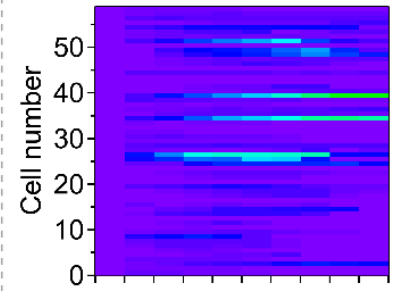

$8.3 \mathrm{ng} / \mu \mathrm{L}$

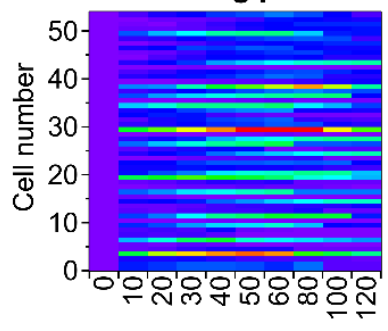

Time (min)
$2.1 \mathrm{ng} / \mathrm{ML}$

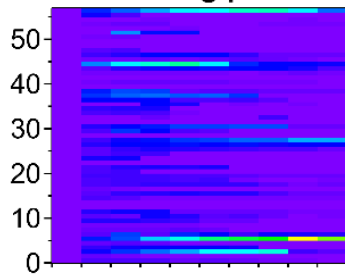

$41 \mathrm{ng} / \mu \mathrm{L}$

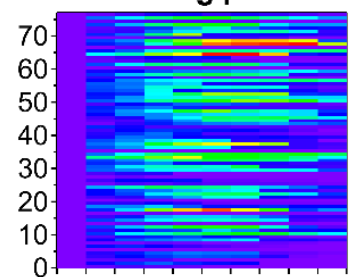

$2.1 \mathrm{ng} / \mu \mathrm{L}$

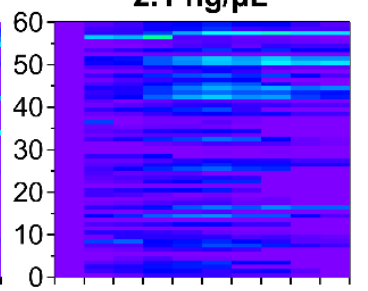

$41 \mathrm{ng} / \mu \mathrm{L}$
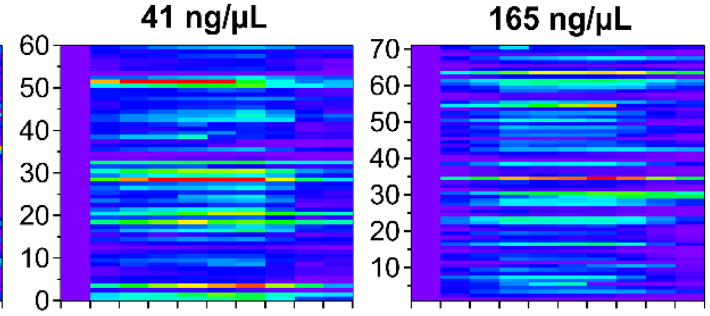

$2.1 \mathrm{ng} / \mathrm{\mu L}$

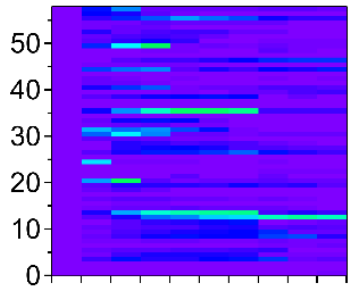

3rd trial

$41 \mathrm{ng} / \mu \mathrm{L}$

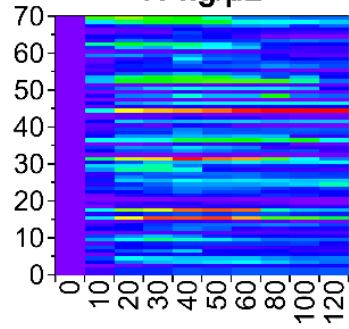

Time (min) 2nd trial

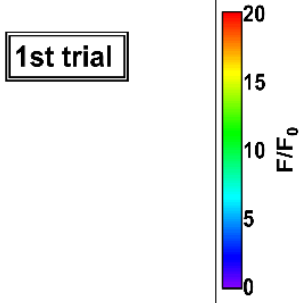

$165 \mathrm{ng} / \mu \mathrm{L}$

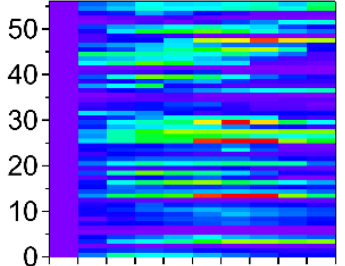

trial

Figure S6. Heat maps of single-cell traces of ROS fluorescent intensity $\left(\mathrm{F} / \mathrm{F}_{0}\right)$ induced

107 by five different concentrations of the PM extracts in three independent trials. The cells

108 are numbered in an order of cells following the flow from inlet to outlet of the device. 

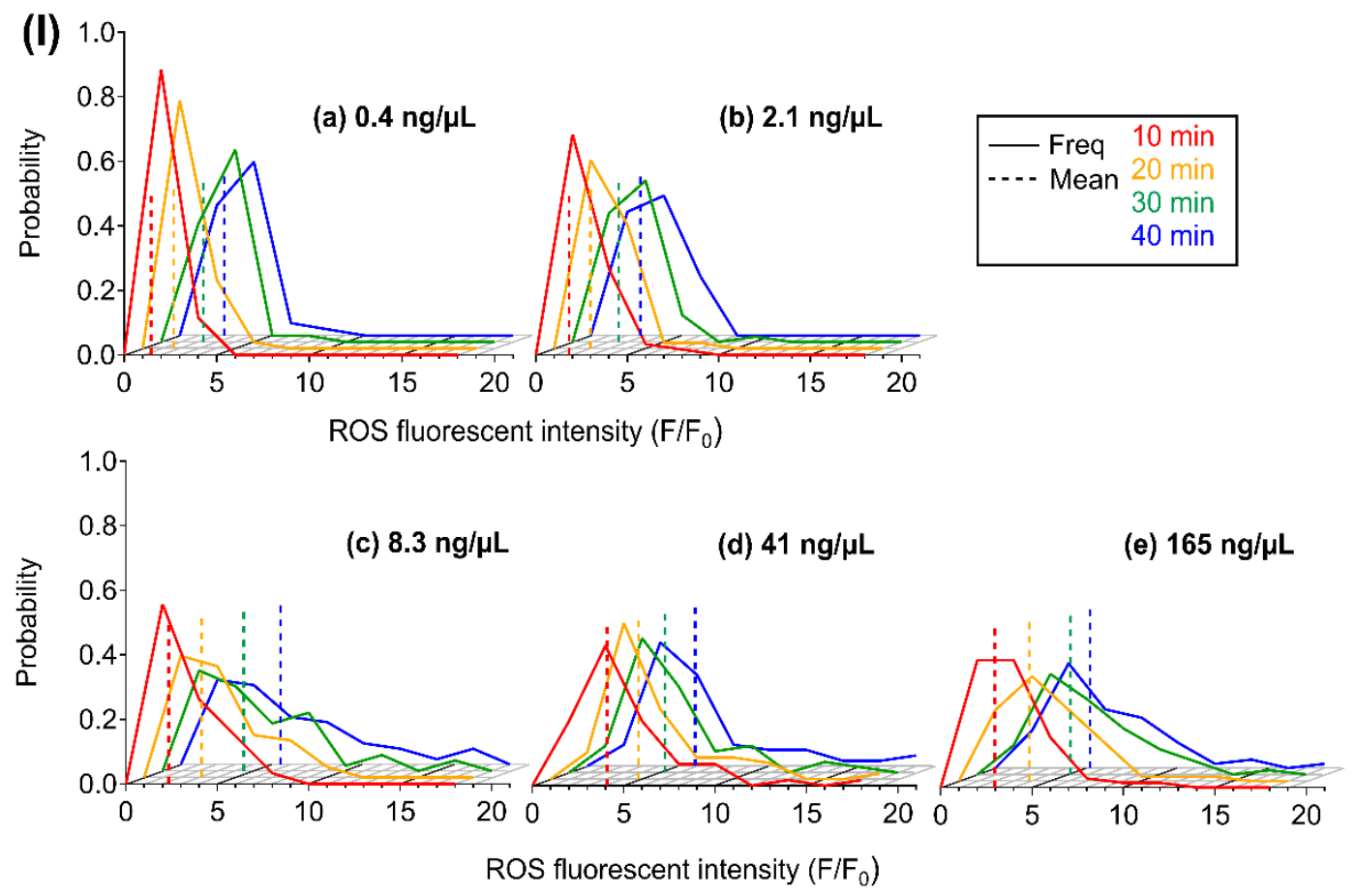

109
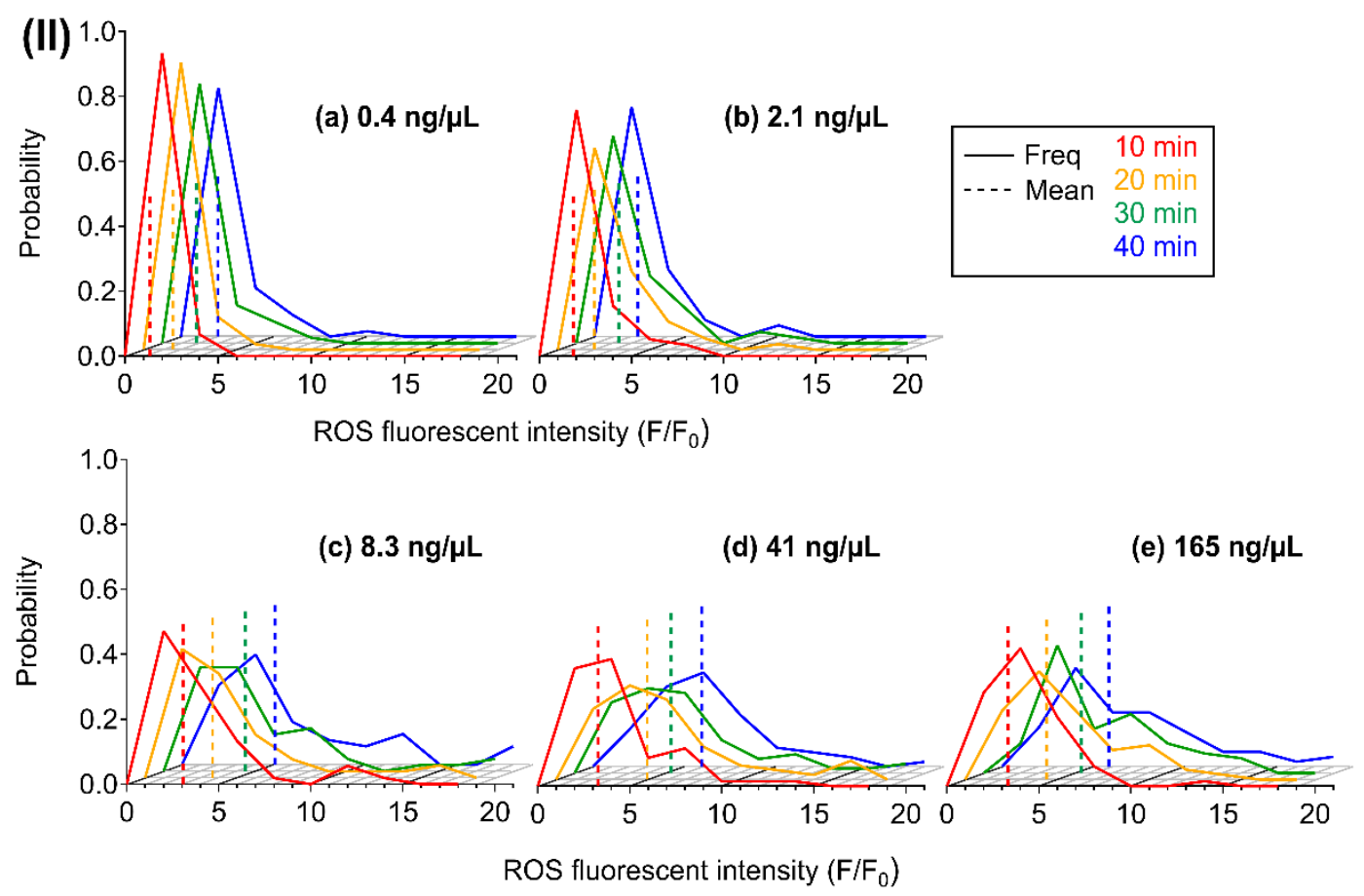

Figure S7. Histogram analysis of normalized ROS fluorescent intensity $\left(\mathrm{F} / \mathrm{F}_{0}\right)$ for cells 112 exposed to five different concentrations of the PM extracts at $10 \mathrm{~min}$ (red), $20 \mathrm{~min}$ 113 (orange), $30 \mathrm{~min}$ (green), and $40 \mathrm{~min}$ (blue) in the second (I) and third (II) trials. The 114 dashed lines are average ROS fluorescent intensity at each timepoint. 

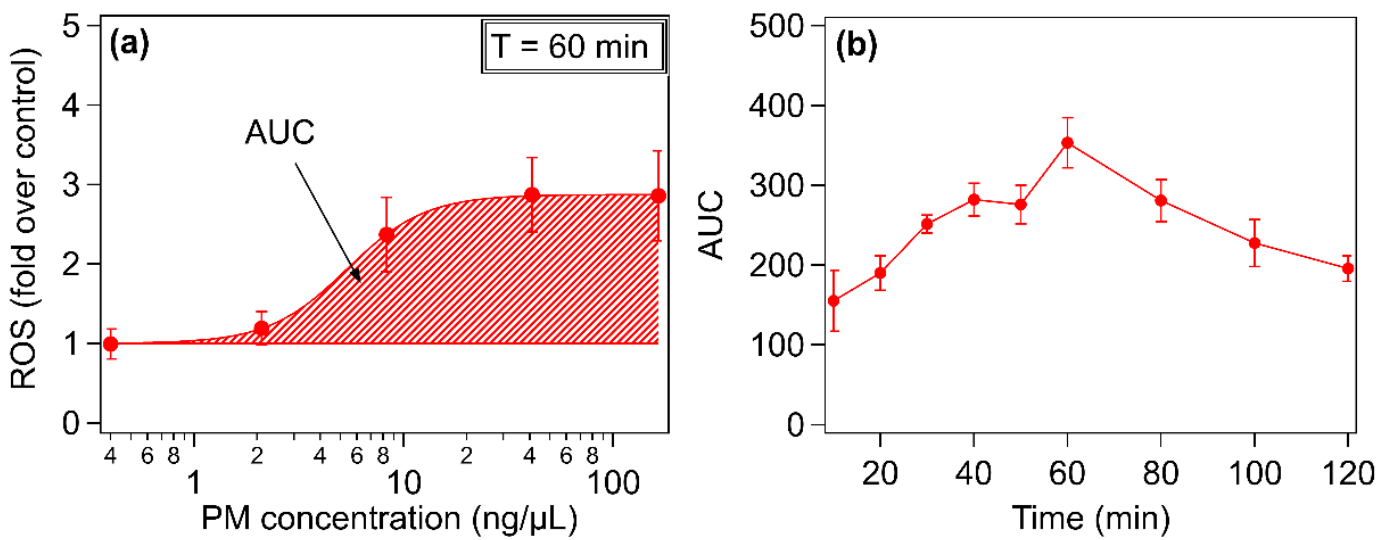

116 Figure S8. (a) Representative dose-dependent curve of ROS responses upon PM

117 exposure (a PM 2.5 filter sample collected at the Jefferson Street site in Atlanta; sampling 118 date: August 19, 2017). Data and error bars represent mean values and standard errors 119 calculated from single cell measurements in the first trial. The exposure time is $60 \mathrm{~min}$.

120 The curve is fitted by the Hill equation and the AUC (area under the curve) is 121 calculated. ${ }^{5}$ (b) Temporal evolution of AUC (area under the curve) values obtained at 122 each time point. Data and error bars represent mean values and standard errors from 123 three independent trials. 


\section{References}

126 1. Gowen, B. B.; Borg, T. K.; Ghaffar, A.; Mayer, E. P., Selective adhesion of 127 macrophages to denatured forms of type I collagen is mediated by scavenger 128 receptors. Matrix. Biol. 2000, $19(1), 61-71$.

129 2. Koyama, Y.-i.; Norose-Toyoda, K.; Hirano, S.; Kobayashi, M.; Ebihara, T.; 130 Someki, I.; Fujisaki, H.; Irie, S., Type I collagen is a non-adhesive extracellular matrix 131 for macrophages. Arch. Histol. Cytol. 2000, 63 (1), 71-79.

132 3. Halldorsson, S.; Lucumi, E.; Gómez-Sjöberg, R.; Fleming, R. M., Advantages 133 and challenges of microfluidic cell culture in polydimethylsiloxane devices. Biosens. 134 Bioelectron. 2015, 63, 218-231.

135 4. Lu, H.; Guo, L.; Kawazoe, N.; Tateishi, T.; Chen, G., Effects of poly (L-lysine), 136 poly (acrylic acid) and poly (ethylene glycol) on the adhesion, proliferation and 137 chondrogenic differentiation of human mesenchymal stem cells. J. Biomater. Sci. 138 Polym. Ed. 2009, 20 (5-6), 577-589.

139 5. Tuet, W. Y.; Fok, S.; Verma, V.; Rodriguez, M. S. T.; Grosberg, A.; Champion, 140 J. A.; Ng, N. L., Dose-dependent intracellular reactive oxygen and nitrogen species 141 (ROS/RNS) production from particulate matter exposure: comparison to oxidative 142 potential and chemical composition. Atmos. Environ. 2016, 144, 335-344. 